\title{
Moving Towards Integrated Policy Formulation and Evaluation: The Green Economy Model
}

\author{
Andrea M. BASSI ${ }^{1,2 *}$ \\ ${ }^{1}$ School of Public Leadership, Faculty of Economic and Management Sciences, Stellenbosch University, \\ Private Bag X1, Stellenbosch 7602, South Africa \\ ${ }^{2}$ KnowlEdge Srl, 35, via Col Di Lana, Castellanza 21053, Italy
}

\begin{abstract}
The mainstreaming of concepts related to the Green Economy, an action-oriented approach to reach sustainable development, has increased demands for integrated models that can shed light on the complex relations existing across social, economic and environmental indicators. A gap exists, whereby our thinking is rapidly evolving, but the tools available are still in the vast majority of cases sectorial, leading to planning processes taking place in silos. To avoid the emergence of side effects, and anticipate future threats and opportunities, a more systemic approach is needed. The Green Economy Model (GEM) was created taking into account four main capitals and their interconnections: physical capital, human capital, social capital and natural capital. The application of GEM in 10 countries has shown its capability to coherently represent reality and generate results that can more effectively inform decision making.
\end{abstract}

Keywords - Green Economy; System Dynamics; simulation; model; policy; natural capital

\section{INTRODUCTION}

The interconnections between socio-economic development and the environment (quality and availability of natural capital) have become more visible over the past decade, urging policy makers to adapt and improve the policymaking process to find more durable solutions. In this context, the analysis of historical data and future scenarios is crucial to enable decision-makers to fully understand the strengths and weaknesses, as well as synergies and bottlenecks, of possible green economy intervention.

When considering the current policy context, most countries are confronted with requests from the international community, while at the same time having to deal with national and local priorities. In this respect, the international community has recently changed its approach, promoting the use of frameworks for the creation of coherent policies, rather than proposing solutions to national problems. The discussions on Sustainable Development, Green Economy and Green Growth, as well as climate mitigation in the context of COP21 (through the INDC pledges) fall in in this category.

Starting from the highest level of policy framework, the report by the United Nations Environment Management Group's [1] points out that, at the operational level, the green economy is seen as one whose growth in income and employment is driven by investments that (1) reduce carbon emissions and pollution; (2) enhance energy and resource efficiency; (3) prevent the loss of biodiversity and ecosystem services. These investments need to be catalysed and supported by targeted public expenditure, policy reforms and regulation changes to create the so-called "enabling conditions" for an inclusive green economy. More specifically, the main policy interventions proposed by UNEP include: (a) addressing environmental externalities and

\footnotetext{
* Corresponding author.

E-mail address: andrea.bassi@ke-srl.com
} 
existing market failure; (b) limiting government spending in areas that deplete natural capital, by removing harmful subsidies and incentives; (c) promoting investment and spending in areas that stimulate a green economy; (d) establishing a sound regulatory framework to accelerate progress towards a green economy and equitable allocate costs and benefits across key economic actors. A common purpose of green economy policies and investments is the maintenance, enhancement and rebuilding of natural capital as a critical economic asset and source of public benefits. Protecting natural resources, from clean freshwater to forests and air, is especially important for poor people who depend on these resources for their livelihoods and are especially vulnerable to environmental contamination and degradation. In short, the green economy represents an attempt to mobilize more action-oriented pathways to sustainable development.

This being said, large-scale and interconnected infrastructure projects (as enablers of economic development [2]) are shown to profoundly influence the integrity of natural systems [3], [4]. The benefits for society and economies -national and regional- of infrastructure investment are analysed to assess whether the project will lead to the desired economic outcomes, whatever these may be [5]. Yet, the risks to complex natural systems that the world relies on for food, water, and energy, are rarely considered in this process; even though this risk presents potential economic costs that could outweigh the benefits of the project proposed [6]. Increasingly strained by climate change and the demands of a growing human population, the pressure on our "stores" of natural capital is mounting [7]. Under pressure, natural systems (which can be considered as "ecological infrastructure") become less stable and resilient [8], [9]. In short, there are unintended and unforeseen consequences of the physical construction of infrastructure projects that jeopardise economic development goals that are longer term or difficult to measure in financial terms [10]. This highlights an important disconnect between the policy framework that is being proposed, and the way projects are being conceptualized and implemented.

If the complementary goals of economic progress, social development and inclusiveness are to be achieved, there needs to be change in business practices, government decision making and investment in infrastructure to favour maintaining natural capital while cultivating human and economic capital. As such, the economic opportunity from transport, urban, ICT, etc. infrastructure must be balanced against long-term need for natural systems vital to economic and physical resilience [11]. Planning infrastructure development for maximum benefit to regional/national economies and local communities requires methods and tools that include those benefits gained from maintaining natural capital. Many such tools are being put forward to inform decision-making in various initiatives by bilateral development partners, International Governmental Organisations and Civil Society Organisations, academics [12], [13] and even private sector consulting firms. By and large, these approaches attempt to analyse and estimate various dimensions of the short, medium and longer-term outcomes of infrastructure investments. But the results being produced by these tools are not all that useful for decisionmakers because they are not appropriate for the full scope of the context.

This paper presents a GEM, explicitly created to support the integrated policy processes required to reach sustainable development, using a green economy approach. The model was developed using existing knowledge and integrating available tools, making use of their strengths, and has been applied in 10 countries so far. These include very diverse regions, and customizations of the model were made for, among others, Serbia and Moldova, Mozambique and Mauritius, as well as Indonesia and Myanmar. 


\section{Literature ReVIEW AND THE MODELling GAP}

\subsection{Models for Green Economy Policy Analysis}

Moving towards a greener economy involves the design and implementation of key interventions such as public expenditure, policy reforms and regulation changes that aim to foster sustainable economic growth, employment generation, inclusive income opportunities, and environmental conservation. As a result, methodologies and models are needed in order to support policymakers in the assessment of cross-sectorial economic, social and environmental impacts of green economy policies. In particular, methodological approaches and models should allow to quantitatively project and evaluate trends (for issue identification), identify entry points for interventions and set targets (for policy formulation), assess ex-ante the potential impact across sectors and the effectiveness in solving stated problems (or exploiting opportunities) of selected interventions (for policy assessment), as well as monitor and evaluate the impact of the interventions chosen against a baseline scenario (for policy monitoring and evaluation ex-post assessment / analysis).

Various methodologies can be utilized to support policy formulation and assessment. These methodologies can be divided into two main categories: (1) static data frameworks and (2) dynamic modelling approaches. Data frameworks are "static", and can be used either in isolation, to investigate and understand the history (past trends) and current state of the system, or embedded in simulation models, to generate simulations of future trends for all the indicators included in the framework selected. Data frameworks often represent the backbone of models, also depending on the flexibility and degree of customization offered by the modelling approach utilized. The data frameworks most commonly used at the national level include (1) indicators; (2) Input-Output frameworks; (3) Social Accounting Matrix; and (4) Geographic Information System (GIS). These data frameworks are generally used to create and calibrate models. In particular, quantitative simulation models are developed following modelling approaches, which are their underlying mathematical theories and frameworks. These methodologies could be considered "dynamic" as they allow generating future projections and include (1) econometrics, measuring the relation between two or more variables, running statistical analysis of historical data and finding correlation between specific selected variables; (2) optimization, prescriptive models providing information on what to do to make the best of a given situation ; and (3) System Dynamics (or simulation), used to create models that are descriptive, focuses on the identification of causal relations influencing the creation and evolution of the issues being investigated.

When comparing these modelling approaches, it becomes evident that while no model can capture all the facets of the green economy, coupled optimization models and System Dynamics could potentially satisfy most of the criteria required to inform policymaking. More specifically, Input-Output (I-O) models can provide a high level of sectorial disaggregation and generate results analysed across the value chain of selected products and technologies, tracking employment, material and/or emission flows. Regional I-O models extend this analysis to trade among countries. These models can capture economic and human capital, Sustainable Consumption and Production (SCP) and competitiveness, as well as support investment analysis. Energy and other system engineering (optimization) models specifically focus on one or two sectors and can track manufactured capital (even if expressed in physical terms, as built up capital), climate change mitigation options (e.g., in the case of energy) and potentially also climate change adaptation (e.g., in the case of water) [14], [15]. These models can support both green economy investment and policy analysis (especially regulation). GIS-based models (e.g., InVEST) [16], being spatially disaggregated and focusing on land use changes, specialize in 
natural capital and are able to capture ecological scarcities and environmental risks. These tools can also support the analysis of human well-being, with access to resources and vulnerability to climate change, being capable of analysing impacts, mitigation (especially sinks, through land use) and adaptation options. Spatial models are generally better suited to analyse policy impacts (e.g., regulation), rather than green economy investments. Computable General Equilibrium (CGE) models cover the economic sphere of sustainable development, accounting for manufactured capital, competitiveness and social equity (e.g., through the estimation of income distribution) [17]. Human capital can also be estimated, despite methodological constraints, regarding employment, skills, as well as salary and wages. CGE models can effectively support both investment and (fiscal and monetary) policy analysis. When coupled with system engineering models, CGEs can more effectively incorporate natural capital (primarily by representing natural resource stock and flows) and ecological scarcities. This allows for a fuller estimation of competitiveness, also including SCP and the analysis of capital misallocation (now possible due to the cross-sectorial nature of the model, capable of estimating ecological scarcities). Moreover, by adding natural resources, the model would be able to analyse climate change mitigation and adaptation options, and make use of spatial information to potentially incorporate impacts as well. Finally, System Dynamic models, both sectorial and integrated, can endogenously represent economic, human and natural capital [18], [19]. The strength of the model and the level of detail of the analysis depend on the identification and understanding of the key drivers of the system, and on the availability of inputs from more detailed employment and natural capital assessments. By accounting for natural resource stocks and flows, ecological scarcities can be estimated, with resulting environmental risks and vulnerabilities (incorporated using results of an InVEST analysis, for instance). At the economic level, given the typical high level of aggregation of System Dynamic models, SCP could be simulated and analysed from a macro perspective, tracking consumption of the most relevant inputs to production (especially natural resources). Concerning social dimensions, while social equity would be estimated through income distribution, the calculation of human well-being could use indicators from a variety of sectors, including environmental ones.

\subsection{Existing Gaps}

Current explorations point to the need for more appropriate decision-support tools for development bank investors and public decision-makers that include quantified negative environmental externalities for both local communities and national economic priorities including sectorial development, poverty reduction, and job creation [20]. This is because most impact assessment tools are designed to evaluate one single dimension of development (i.e. economic, social or environmental), and only their combined use is likely to provide effective support to decision making. Moreover, many tools and methodologies have been developed following frameworks that cannot be easily customized to the local context, which prevent analysts and decision makers from utilizing the results of the assessment to inform their specific development priorities [21].

The main issues observed so far include: (1) poor reconciliation of costs and benefits at different scales/strong focus on traditional/unsustainable development; (2) lack of adequate responses for the complexity of the problem.

Almost universally, decision makers at all levels are less concerned with single issues in their own right, and much more concerned with the impact of these issues on their bottom line economic growth, social equity, geopolitical stability and national security. In theory, we all know that the quality of our environment is directly linked to these bottom line issues, but it is not enough to show this in the abstract. In economics, we use a wide range of real-time 
connected economic indicators to build a robust picture of economic "stocks and flows" in a country, and we then package and communicate these complex assessments to other communities using aggregate indicators such as GDP. This is the type of integrated system we need for green economy; a system that provides a clear understanding of the quantity and quality of environmental "stocks and flows" on a given landscape, allowing us to link these indicators to the health, livelihoods, and security of people at the scales and in the locations that matter to decision processes.

Optimization is by far the most commonly used methodological approach to support policy formulation and assessment. The intervention that minimizes costs, or maximizes utility, is generally the one chosen. While from a sectorial perspective this may seem like a good approach, the consequences of any sectorial intervention will be felt in other sectors and by several actors. These indirect and induced outcomes of policy implementation may be positive (e.g. creating synergies) or negative (e.g. creating side effects and additional costs). In other words, an intervention that can be considered "optimal" at the sectorial level may well create problems from a system perspective, such as in the case of the overexploitation of natural resources. In the context of large-scale infrastructure projects, optimization is generally done on the basis of cost and location.

\section{GEM TECHNICAL SPECIFICATIONS}

Finding that most currently available national planning models are either too detailed or narrowly focused [19], this study proposes an approach that: a) extends and advances the policy analysis carried out with other tools by accounting for the dynamic complexity embedded in the systems studied; and b) facilitates the investigation and understanding of the relations existing between natural capital, society and the economy. The inclusion of cross-sectorial relations supports a wider analysis of the implication of alternative green economy policies, and the longterm perspective proposed allows for the identification of potential side effects and sustainability of different strategies.

The approach proposed uses the System Dynamics (SD) methodology as its foundation, serving primarily as a knowledge integrator. System dynamics modelling is a form of computer simulation modelling designed to facilitate a comprehensive approach to development planning in the medium to long term [22]-[24]. A key characteristic of SD is that it allows us to integrate the three spheres of sustainable development in its analytical process. SD operates by simulating historical data for a period of at least one decade, and comparing simulation results with the available data. The purpose of such models is not to make precise predictions of the future; rather, they are a tool for exploring alternative policy scenarios in order to identify those policies that could improve conditions in the future and contribute to the achievement of desired goals and objectives [25], [26].

System Dynamics allows to represent explicitly stocks and flows of human, built and natural capital, and to create linkages among them through the use of feedbacks, delays and nonlinearity. System Dynamics also allows to simultaneously use other modelling techniques, such as optimization and econometrics. In fact, SD has been successfully coupled, in the context of green economy work, with a CGE model in Mexico [27], with InVEST for Borneo [28] and in Thailand [29] and with energy sector optimization models for several countries and in the global green economy modelling work of UNEP.

\subsection{Modelling the Green Economy with GEM}

GEM was designed explicitly to analyse green economy scenarios. As a result, it includes 
several sectors across social, economic and environmental dimensions. The effective integration of these sectors is made through the use of stocks and flows, which brings consistency to the mathematical formulations used to create the model. This integration was possible through several interactions with leading international experts, national researchers, policy makers and members of the community in several countries.

Figure 1 presents the generalized underlying structure of GEM. This diagram shows how the key capitals are interconnected, and contribute to shaping future trends across social, economic and environmental indicators. Specifically, feedback loops can be identified that are reinforcing $(\mathrm{R})$ in all areas pertaining economic growth and social development. These are enabled by the availability of natural capital, which, if not properly managed, can constrain economic growth (hence the balancing loops (B) identified in the diagram). Policies can be implemented to promote sustainable consumption and production, decoupling economic growth from resource use (also through education and behavioural change), to mitigate the exploitation of natural capital and generate a stronger and more resilient green growth.

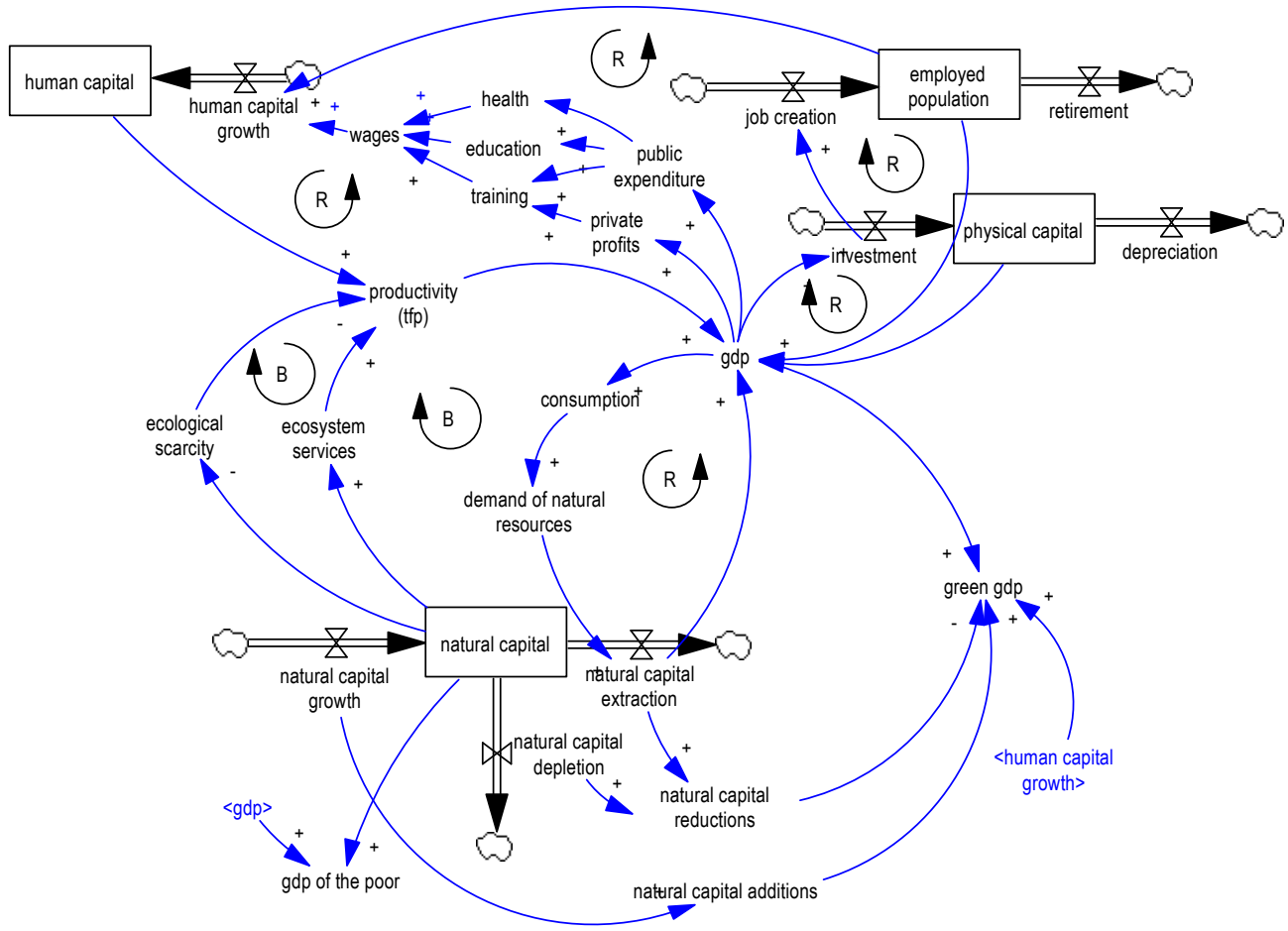

Fig. 1: Causal Loop Diagram (CLD) representing the main variables and feedback loops of GEM applications.

As a result, GEM applications can be used to (1) test the effectiveness of individual policies and investments (by assessing their impact within and across sectors, and for social, economic and environmental indicators); (2) inform budgetary planning, by assessing the effectiveness of annual plans in delivering green and inclusive growth; (3) support the formulation and analysis of development plans that span across sectors and target medium to longer term goals. 
GEM models are customized at the country or landscape level, to properly capture the local context and dynamics. In general, GEM models include the following groups of sectors, to ensure that green economy opportunities are effectively analysed:

- Industrial sectors: embedded in the conventional (carbon-intensive) structure that has contributed to modern life styles and, as proven by various studies, is being challenged by rising energy prices and externalities. Such sectors have to aim for a transition to energy efficient technologies and resource efficiency to prosper while lowering costs and reducing their impact on the environment. Major steps are necessary to retrofit and replace old 'brown' economic structures, to develop innovative regulations, and to introduce new 'green' economic structures.

- Natural capital-based sectors: heavily relying on the availability of natural resources (stocks and flows), these sectors can thrive and be sustainable only if resource extraction is managed so as to maintain the ecosystem balance. Overexploitation of natural resources should be avoided to curb impacts on ecosystem services, which would ultimately undermine productivity and competitiveness.

With the horizontal integration of several sectors having the potential to re-shape consumption and production, the GEM models are able to inform policy formulation and evaluation for emerging economies (those that find themselves increasingly locked into conventional energy and carbon intensive economic structures, but can more easily turn to greener paths than developed countries, as their economies are more flexible and adaptable) as well as developing economies (being less locked into carbon-intensive capital and thus having the unique opportunity to steer their development path towards the new 'greener' economic development paradigm).

As an example of the customization carried out for provincial models in Indonesia, while Indonesia I-GEM, Province of Kalteng KT-GEM and Province of Jakarta JAK-GEM have many similarities in order to facilitate the comparison of results at the national and province level, they have also some:

- Sectorial coverage: I-GEM simulates the impacts of green economy policies across five sectors that are prioritized in national sustainable development plans, including (1) Agriculture; (2) Forestry; (3) Fishery; (4) Energy; and (5) Mining. KT-GEM includes more detail on land use, and also accounts for tourism and transport infrastructure (roads), which is also very relevant (and represented in high level of detail) in the Jakarta model.

- GDP of the poor: in KT-GEM the estimation of the GDP of the poor focuses on villages whose economy is reliant on four types of natural resources, namely (1) coal; (2) forest; (3) rivers; or (4) rattan. In JAK-GEM instead households are disaggregated according to different economic activities, as follows: (a) river, (b) coast side, (c) industrial, (d) government housing.

- Peat land: emissions from peat land and peat fires are a growing concern for local authorities in Central Kalimantan. Consequently, a Peat Land module was added to KTGEM in order to estimate the expected reduction in peat land emissions deriving from green economy interventions at the provincial level.

\subsection{The GEM Modelling Framework}

The GEM is well suited to: (1) generate projections of future developments (though acknowledging that long term accurate projection cannot easily be produced, even when simulating a large number of endogenous key variables); (2) provide an integrated analysis and evaluation of policy choices; and (3) increase the understanding of the relations underlying the 
system analysed. The following paragraphs briefly describe the principal aspects of the GEM application customized to Mauritius.

Boundaries: Variables that are considered an essential part of relevant development mechanisms are endogenously calculated. For example, GDP and its main determinants, population and its main determinants, and the demand and supply of natural resources are endogenously determined. Variables that have an important influence on the issues analysed, but which are only weakly influenced by the issues analysed, are exogenously represented.

Time horizon: GEM applications are built to analyse medium to long-term green economy scenarios. Also, simulations start in the past in order to allow validation against historical data. In the customization to Mauritius (M-GEM), the time horizon for simulation starts back in 1980 and extends up to 2030 .

Structure: despite the variety of green economy opportunities considered, GEM is a relatively small model. Its complexity lies in the high number of cross-sectorial linkages (dynamic complexity), but its vertical detail (within a sector, or detailed complexity) is far from overwhelming. Consequently, the model is fully tailored to a green economy analysis, being based on stakeholder inputs, and does not compete with the models already being used by the government and its partners. In fact, GEM is developed to fill a gap in the current modelling work in relation to the green economy, and to identify research needs to be addressed with more detailed sectorial models.

The main outputs of GEM, and of the green economy analysis carried out with it, include the investment required to implement the intervention desired, added benefits and avoided costs. Among the benefits, indicators include sectorial value added (as driven by natural resources stocks and flows, e.g. sustainable agriculture yield and production), direct employment creation and relative income generated, e.g. additional employment in public transport or energy efficiency sectors. Avoided costs include savings from avoided consumption (e.g. water, through resource efficiency interventions), and potential avoided ecosystem restoration costs. These are compared with costs, and potential damages created by the business as usual case and by the policy implemented, to estimate the economy-wide annual cash flow, as well as the break-even point, and the return on investment (and, for instance, the return on employment, and emissions).

By generating systemic, broad and cross-sectorial scenarios over time that address environmental, economic, and social issues in a single coherent framework, the GEM simulates the main short-, medium- and longer-term impacts of investing in a greener economy. The most important contribution of this model is its systemic structure that includes endogenous links within and across the economic, social, and environmental sectors through a variety of feedback loops. Most existing models focus on one or two sectors and make exogenous assumptions about other sectors that affect and are affected by the sector under consideration. Using endogenous formulations instead improves consistency over time and across sectors, because changes in the main drivers of the system analysed are reflected throughout the model and analysis through feedback loops. While detailed sectorial analysis is very important, it is not adequate to demonstrate the whole set of relations and feedback loops that properly represent the functioning of the real world and that have to be taken into account in making the necessary transitions to greener economic and social structures.

\subsection{Natural Capital Inclusion in GEM}

The key drivers of a greener economy, as represented in the models customized for the analysis carried out in several countries, are stocks and flows. Stocks are accumulations of inflows and outflows (such as forests are the accumulation of reforestation and deforestation). In the economic sectors of the GEM, GDP is primarily influenced by stocks, such as capital and 
labour. Going beyond this simplistic view, in the GEM we consider that capital and labour are needed to develop and process natural resource stocks. As a consequence, three key factors often define the transformation of natural resources into economic value added; the availability of capital (which accumulates through investments and declines with depreciation), labour (which follows the demographic development of the planet, being driven by the population of labour age), and stocks of natural resources (which accumulate with natural growth -when renewableand decline with harvest or extraction). Examples of the direct impact of natural resources on GDP are the availability of water and fertile land for agricultural production, as well as the availability of fossil fuels to power the capital needed to irrigate and harvest crops, among others. In addition, GEM country applications include the estimation of ecosystem services (e.g. as a result of land use change). The ecosystem services modelled include water yield and water quality, the availability of non-timber forest products (NTFP), soil erosion and nutrient loadings, as well as carbon sequestration. In this respect, the GEM accounts for both monetary and physical variables, representing each sector in a coherent and consistent manner with the economic valuation of ecosystem services being carried out using TEEB guidelines and the incorporation of models such as InVEST.

\subsection{Scenario Setup}

The simulation of GEM scenarios generally starts between the year 1980 or 2000 and ends in 2040, allowing for historical behavioural validation over a period of more than 30 years at times and to assess the impacts of policy interventions throughout the lifecycle of investments.

Two main scenarios are simulated and analysed in this report, as presented below.

- A Business as Usual (BAU) case that assumes the continuation of historical and present trends. This includes all policies and interventions currently active and enforced, but excludes policies planned but not yet implemented.

- A set of Green Economy (GE) scenarios that simulate green economy policies in key sectors, including, for instance, agriculture, energy, industry, tourism, waste and water. The sectoral policies simulated in the case of Mauritius under the green economy scenarios are listed in Table 1. These interventions can be tested and analysed in isolation (i.e. one by one) or simultaneously, to assess their short, medium and long term impacts across social, economic and environmental indicators.

\section{TABLE 1. SECTORIAL TARGETS FOR GREEN ECONOMY INTERVENTIONS UNDER THE GREEN ECONOMY SCENARIOS, MAURITIUS}

\begin{tabular}{|c|c|}
\hline Sector & GE interventions \\
\hline Agriculture & $\begin{array}{l}\text { - Increase self-sufficiency levels in strategic commodities targeted under the Food Security Fund } \\
\text { from } 56 \% \text { in } 2012 \text { to } 90 \% \text { in } 2025 \text {. } \\
10 \% \text { agriculture arable land is converted to ecological agriculture (organic fertilizers and } \\
\text { certifications) by } 2025 \text {. }\end{array}$ \\
\hline Energy & $\begin{array}{l}\text { - Increase renewable energy penetration up to } 35 \% \text { by } 2030 \\
\text { - } \quad \text { Increase energy efficiency by } 10 \% \text { in } 2020 \text { and } 20 \% \text { in } 2030 \text {. }\end{array}$ \\
\hline Industry & $\begin{array}{l}\text { - Increase energy efficiency in manufacturing increased by } 10 \% \text { by } 2020 \text { and by } 20 \% \text { by } 2030 \text {, } \\
\text { relative to } 2010 \text {. } \\
\text { - Increase water efficiency in manufacturing by } 20 \% \text { by } 2030 \text {. }\end{array}$ \\
\hline Tourism & $\begin{array}{l}\text { - Increase energy efficiency in tourism increased by } 10 \% \text { by } 2020 \text { and by } 20 \% \text { by } 2030 \text {, relative } \\
\text { to } 2010 \text {. } \\
\text { Increase water efficiency in tourism by } 20 \% \text { by } 2030 \text {. }\end{array}$ \\
\hline Waste & - Increase recycling from $12 \%$ in 2012 to $50 \%$ by 2025 . \\
\hline Water & - Increase economy-wide water use efficiency by $20 \%$ by 2030 \\
\hline
\end{tabular}




\section{Country Customizations AND Applications}

\subsection{GEM Applications at the Country Level}

\subsubsection{Indonesia}

The main interventions analysed in the customization of GEM to the province of Central Kalimantan (Kalteng) in Indonesian Borneo include reduced deforestation, the expansion of organic agriculture, and the faster adoption of decentralized, off-grid renewable energy.

The green economy scenario for Kalteng projects beneficial impacts for GDP, jobs creation, household incomes, agriculture, energy and $\mathrm{CO}_{2}$ emissions. Recognition of the critical role that green economy interventions can play in encouraging the economy of Kalteng is important for future policy decisions to improve competitiveness and encourage growth. Initiatives like the Mega Rice Project which viewed peatlands in Kalimantan only as areas for cultivation and consequently resulted in environmental damage values more than the gains in economic activity. These impacts could be avoided with increases in land productivity and the potential market price premium for sustainable, eco-labelled, products. Further, one of the indirect impacts of the same intervention (sustainable agriculture) is that higher production can be achieved while also lowering the requirements for land for cultivation (therefore improving the livelihood of local communities that heavily rely on natural capital for subsistence). Therefore, enhancing food security, a policy result that is desired, can be achieved more effectively through green interventions and through better access to markets for improved returns for sustainable products. Thus, KT-GEM provided the justification for policymakers in Kalteng to invest in training farmers and providing support for ecological practices to be adopted to increase yields, for instance.

In the case of the province of Jakarta instead, the model was used to simulate interventions on fossil fuel subsidy removal, green buildings (with specific focus on energy efficiency improvements), and transport, focusing on emission reduction interventions.

Both GDP and Green GDP were projected with GEM, highlighting the net contribution of using a systemic approach that explicitly takes natural capital into account. In particular, the best performance is obtained when coupling fossil fuel subsidy removal with a reallocation to the poor and to capital investments, in conjunction with transport (i.e., fuel efficiency, bus lanes expansion, and MRT development) and the buildings sector (i.e., energy efficiency improvements). In fact, the removal of fossil fuel subsidies alone (without any additional intervention) is projected to reduce disposable income, consumption and investment, and hence GDP, while improving government accounts. The reallocation of subsidy savings, on the other hand, compensates the negative impacts of the removal of subsidies, leading to faster economic growth, especially when the savings are reallocated to investments. If, in addition to reallocating subsidy savings, when interventions were tested to reduce energy consumption and its cost (directly offsetting the increase in energy prices generated by the removal of subsidies), GDP was projected to grow even faster. This is due to an increased productivity in the use of energy, which, despite being more expensive, has a smaller impact on productive activities and household consumption. Of the many interventions simulated, the reallocation of subsidy savings to the poor is not expected to contribute to economic growth as much as investment (development expenditure). On the other hand, interventions on energy efficiency are projected to impact all sectors, due to a mitigation of energy expenditure.

\subsubsection{Mauritius}

The Mauritius GEM model was customized at the national level, to support the Maurice Ile Durable (MID) Commission. Interventions were tested across sectors, as presented in Table 1. Results of the analysis show that the implementation of green economy interventions, as described in the GE scenario, requires a higher amount of investment relative to the BAU case in the sectors analysed. These investments, both public and private, are estimated to reach approximately $0.9 \%$ of GDP per 
year between 2014 and 2035. On the other hand, these should not be considered to be additional (i.e. on top and above BAU). In fact, it is estimated that GE investments will generate annual savings in the range of $3 \%$ of GDP, which will be allocated to consumption, savings and partly also to investment. As a result, it could be argued that green economy investments lead to better economic outcomes than a BAU investment allocation. Interestingly, while investments will need to be ramped up first and will decline (as a share of GDP) over the medium and longer term, savings are initially small and tend to consistently increase over time. This shows that green economy investments are capable of delivery advantages in the medium and longer term too.

Green Economy investments also prove to be effective in stimulating GDP. The additional investments and avoided savings support economic growth, also by creating employment (e.g. in the waste and energy sector). GDP is projected to be about $6 \%$ higher in the GE case relative to the BAU case, by 2035. It is worth noting that the GE investments tested in the model were not designed to maximize economic growth, instead GE interventions are implemented to create a better balance between society, economy and environment. This would ensure to avoid future costs (e.g. for the landfilling of waste and for fossil fuel imports) and using available financial resources to create a more resilient (e.g. with higher food security) and equitable economy. The results of these interventions include higher water and energy productivity (lowering costs across sectors) and more environment-friendly waste (e.g. increasing recycling) and agriculture (e.g. expanding sustainable agriculture) sectors.

\section{TABLE 2. SUMMARY OF GREEN ECONOMY ECONOMIC RESULT, TOTAL AND BY SECTOR: MAURITIUS}

\begin{tabular}{|c|c|c|c|c|c|c|}
\hline Sector & Category & Unit & 2017 & 2020 & 2025 & 2030 \\
\hline \multirow{6}{*}{ Agriculture } & Investment & \multirow{4}{*}{ Rs million } & 6.37 & 6.82 & 7.43 & 1.49 \\
\hline & Annual average (2014-2030) & & \multicolumn{4}{|c|}{5.20} \\
\hline & Additional value added & & 228 & 453 & 828 & 902 \\
\hline & Annual average (2014-2030) & & \multicolumn{4}{|c|}{558.24} \\
\hline & Value added \% difference & \multirow{2}{*}{$\begin{array}{l}G E-B A U \% \\
\text { difference }\end{array}$} & $5.52 \%$ & $10.07 \%$ & $16.49 \%$ & $16.54 \%$ \\
\hline & Annual average (2014-2030) & & \multicolumn{4}{|c|}{$11.34 \%$} \\
\hline \multirow{10}{*}{ Waste } & Investment & \multirow{4}{*}{ Rs million } & 130.65 & 215.75 & 359.87 & 368.66 \\
\hline & Annual average (2014-2030) & & \multicolumn{4}{|c|}{250.96} \\
\hline & Savings & & 67.67 & 109.7 & 180.56 & 181.46 \\
\hline & Annual average (2014-2030) & & \multicolumn{4}{|c|}{126.02} \\
\hline & Waste mgmt cost \% difference & \multirow{2}{*}{$\begin{array}{c}G E-B A U \% \\
\text { difference }\end{array}$} & $-16.65 \%$ & $-26.64 \%$ & $-43.25 \%$ & $-43.25 \%$ \\
\hline & Annual average (2014-2030) & & \multicolumn{4}{|c|}{$-30.35 \%$} \\
\hline & Additional labour costs & \multirow{2}{*}{ Rs million } & 7.20 & 11.63 & 19.31 & 19.36 \\
\hline & Annual average (2014-2030) & & \multicolumn{4}{|c|}{13.43} \\
\hline & Labour cost $\%$ difference & \multirow{2}{*}{$\begin{array}{c}\text { GE-BAU\% } \\
\text { difference }\end{array}$} & $2.06 \%$ & $3.29 \%$ & $5.39 \%$ & $5.38 \%$ \\
\hline & Annual average (2014-2030) & & \multicolumn{4}{|c|}{$3.77 \%$} \\
\hline \multirow{6}{*}{ Energy } & Investment & \multirow{4}{*}{ Rs million } & 254 & 248 & 423 & 7656 \\
\hline & Annual average (2014-2030) & & \multicolumn{4}{|c|}{1636} \\
\hline & Savings & & 3132 & 3891 & 6233 & 7463 \\
\hline & Annual average (2014-2030) & & \multicolumn{4}{|c|}{4829} \\
\hline & Energy bill \% difference & \multirow{2}{*}{$\begin{array}{l}\text { GE-BAU \% } \\
\text { difference }\end{array}$} & $-8.03 \%$ & $-9.25 \%$ & $-13.21 \%$ & $-14.41 \%$ \\
\hline & Annual average (2014-2030) & & \multicolumn{4}{|c|}{$-20.12 \%$} \\
\hline \multirow{8}{*}{ Water } & Investment in water efficiency & \multirow{4}{*}{ Rs million } & 9.82 & 15.18 & 24.61 & 34.65 \\
\hline & Annual average (2014-2030) & & \multicolumn{4}{|c|}{19.16} \\
\hline & Savings from water efficiency & & 145 & 225 & 365 & 518 \\
\hline & Annual average (2014-2030) & & \multicolumn{4}{|c|}{285} \\
\hline & Water bill \% difference & \multirow{2}{*}{$\begin{array}{l}\text { GE-BAU\% } \\
\text { difference }\end{array}$} & $-5.5 \%$ & $-8.3 \%$ & $-12.5 \%$ & $-17.4 \%$ \\
\hline & Annual average (2014-2030) & & \multicolumn{4}{|c|}{$-10.06 \%$} \\
\hline & $\begin{array}{l}\text { Investment in pipes } \\
\text { replacement }\end{array}$ & \multirow[t]{2}{*}{ Rs million } & 428 & 428 & 428 & 428 \\
\hline & Annual average (2014-2030) & & \multicolumn{4}{|c|}{428} \\
\hline
\end{tabular}




\begin{tabular}{|c|c|c|c|c|c|c|}
\hline & $\begin{array}{l}\text { Savings from pipes } \\
\text { replacement }\end{array}$ & & 332 & 565 & 1098 & 1930 \\
\hline & Annual average (2014-2030) & & \multicolumn{4}{|c|}{858.8} \\
\hline \multirow{9}{*}{ Total } & Investment & \multirow{4}{*}{ Rs million } & 829 & 914 & 1243 & 8489 \\
\hline & Annual average (2014-2030) & & \multicolumn{4}{|c|}{2339} \\
\hline & Savings & & 3986 & 5373 & 8918 & 11208 \\
\hline & Annual average (2014-2030) & & \multicolumn{4}{|c|}{6805} \\
\hline & $\begin{array}{l}\text { Costs (energy. etc.) \% } \\
\text { difference }\end{array}$ & \multirow{2}{*}{$\begin{array}{l}G E-B A U \% \\
\text { difference }\end{array}$} & $-8.57 \%$ & $-10.74 \%$ & $-15.95 \%$ & $-18.38 \%$ \\
\hline & Annual average (2014-2030) & & \multicolumn{4}{|c|}{$-12.63 \%$} \\
\hline & GDP differential & Rs million & 8516 & 11463 & 18818 & 24778 \\
\hline & CO2 emissions difference & \multirow{2}{*}{$\begin{array}{c}\text { GE-BAU \% } \\
\text { difference }\end{array}$} & $-16.07 \%$ & $-16.40 \%$ & $-18.97 \%$ & $-19.24 \%$ \\
\hline & Annual average (2014-2030) & & \multicolumn{4}{|c|}{$-16.17 \%$} \\
\hline
\end{tabular}

\subsubsection{Cambodia}

The GEM model in Cambodia was customized at the landscape level, for the Mekong Flooded Forest (MFF) landscape. The model represents the main causal relations and feedback loops identified by the stakeholders of the project (researchers, WWF staff, national and provincial decision makers). The key messages emerging from the model are the following: The MFF landscape is dynamic, and is characterized by a high degree of interdependence between social, economic and environmental drivers. The BAU growth scenario shows that the more the population and the economy grow, the more the pressure on the environment increases. In fact, with limited biocapacity (also affected by developments upstream) the construction of a planned hydropower dam is expected to have positive economic impacts, which will lead to higher consumption (and exploitation of natural resources). As a result, the construction of the dam and economic growth, several side effects emerge, that reduce productivity and economic development (especially for the local population) in the medium and longer term. In fact, the increased pressure on the environment results in higher environmental degradation. And that, ultimately, affects the local economy as well as society (though health impacts as well as food prices). In the model, this is highlighted by the fact that economic reinforcing loops trigger social and environmental balancing loops. The former (reinforcing loops) dominate in the short term, balance is found in the medium term, and the latter (balancing loops) become stronger in the longer term. A key conclusion from the study, argued by local stakeholders, is that, given the trade-offs emerging from the analysis, alternative development paths need to be explored to ensure that we simultaneously can increase economic performance (while maintaining equity), and avoid side effects, such as environmental degradation.

\subsubsection{Mozambique}

The simulation of Green Economy scenarios in Mozambique focuses on the energy, fishery, forestry and mining sectors. These are representative of the challenges and opportunities being faced by the country as it embark in the green economy transition. The outcomes of the green economy scenarios for fishery and mining are presented below.

Investing to reduce overfishing is projected to avoid the progressive decline in fisheries productivity and catch, allowing to fish stock to rebuild and leading to better results (over time and relative to the business as usual case) from 2040. In this context, while the value of natural capital (fish stock) will increase and per capita income for fishermen will also grow, compensation measures will be needed for retiring capacity to avoid the increase in illegal fishing activities. According to the projections, these costs will be incurred in the short term, while gains will emerge in the medium and long term.

Reducing the impact of extractive industries on the environment (i.e. water pollution) is a growing concern for the rapidly growing mining sector in Mozambique. Scenarios were simulated to assess 
the potential magnitude of the issue, and the repercussions on the profitability of the sector, as well as of the population leaving in the areas affected. It is shown that saving for the public sector may be accrued if interventions are implemented by the private sector (e.g. reducing pollution rather than investing in water treatment downstream).

Finally, it can be seen that the interventions simulated either reduce the cost of environmental damage or increase the value of natural capital, contributing to a more resilient future. The policies simulated would allow to reduce $\mathrm{CO}_{2}$ emissions (both by lowering sources -energy- and increasing sinks -forest-) and improve the state of the environment by increasing stocks (e.g. fishery and forestry) and by lowering pollution (e.g. mining).

\section{CONCLUSION}

The lack of economic evidence for the role that sustainable ecosystems and natural resource management play in economic and social development [30] has greatly influenced decision making in the past decades. Bluntly stated, the value of maintaining natural capital is not always obvious to decision-makers and stakeholders choosing pathways to economic development [31]. Additionally, although the systemic linkages between economic, social and environmental dynamics are increasingly being discussed and understood at the strategic/visionary level, sectorial policies and investment decisions are still designed in silos, showing a reticence to deviate from "tried and tested" though unsustainable development pathways [32]. This makes a transition to balancing short-term economic benefits of infrastructure investment against the long-term needs for ecosystem integrity and equitable human development a fraught exercise. Development planning requires that financial analyses for infrastructure projects as well as public budgetary processes incorporate economic assessments of social and environmental impacts. One critical need for policymaking is to overcome the silo between social, environmental and economic assessment to generate information that can support infrastructure project decision-makers effectively.

This paper has presented the Green Economy Model (GEM), a simulation model created to address these gaps and provide policymakers with a tool that explicitly includes the relationships existing between society, the economy and the environment. Key feedback loops were identified with leading international and local experts, as well with local members of the community and policy makers. The customization and the application of this model in different country contexts shows that the potential impact of neglecting the relationship between the environment and the economy can greatly influence decision making. In this respect, the simultaneous presence of reinforcing and balancing loops that show potential constraints to growth (by using stocks and flows) allows model users to better understand the dynamics of the system analysed and to design better policies.

GEM is considered to be an ever evolving model. Its structure needs to be constantly customized to reflect the local context, as well as improved to incorporate advances in science (e.g. for the estimation and valuation of ecosystem services). Being fully stakeholder driven, GEM can serve different purposes, which calls for extensive structural and behavioural validation.

\section{REFERENCES}

[1] UNEP. Towards a Green Economy: Pathways to Sustainable Development and Poverty Eradication, 2011.

[2] Fulmer J. What in the world is infrastructure? Infrastructure Investor 2009:(July/August):30-32.

[3] Goodenough R., Page S. Evaluating the environmental impact of a major transport infrastructure project: the Channel Tunnel high-speed rail link. Applied Geography 1994:14(1):26-50. doi:10.1016/0143-6228(94)90004-3

[4] Makki T., Fakheran S., Moradi H., Iravani M., Senn J. Landscape-scale impacts of transportation infrastructure on spatial dynamics of two vulnerable ungulate species in Ghamishloo Wildlife Refuge, Iran. Ecological Indicators 2013:31:6-14. doi:10.1016/j.ecolind.2013.03.001

[5] Jones H., Moura F., Domingos T. Transport Infrastructure Project Evaluation Using Cost-Benefit Analysis. Procedia - Social and Behavioral Sciences 2014:111:400-409. doi:10.1016/j.sbspro.2014.01.073 
[6] Arce R., Gullòn N. The application of Strategic Environmental Assessment to sustainability assessment of infrastructure development. Environmental Impact Assessment Review 2000:20(3):393-402. doi:10.1016/S01959255(00)00050-0

[7] WWF. Living Planet Report, 2014.

[8] Millennium Ecosystem Assessment. Ecosystems and Human Well-being: General Synthesis. Island Press, Washington, DC, 2005.

[9] Helm D. Taking natural capital seriously. Oxford Review of Economic Policy 2004:30(1):109-125. doi:10.1093/oxrep/gru005

[10] Noldan B., Janoušková S., Hák T. How to understand and measure environmental sustainability: Indicators and targets. Ecological Indicators 2012:17:4-13. doi:10.1016/j.ecolind.2011.04.033

[11] Ulgiati S., Zucaro A., \& Franzese P. Shared wealth or nobody's land? The worth of natural capital and ecosystem services. Ecological Economics 2011:70(4):778-787. doi:10.1016/j.ecolecon.2010.11.015

[12] Waddell P., Liming W., Xuan L. URBANSIM. In: Planning Support Systems for Cities and Regions. Cambridge, MA: Lincoln Institute for Land Policy, 2008.

[13] Learmonth G., Smith D., Sherman W., White M., Plank J. A Practical Approach to the Complex Problem of Environmental Sustainability. The Innovation Journal: The Public Sector Innovation Journal 2011:16(1).

[14] Fishbone L. G., Giesen G., Goldstein G., Hymmen H. A., Stocks K. J., Vos H., Wilde D., Zöcher R., Balzer C., Abilock H. User's Guide for MARKAL. IEA Energy Technology Systems Analysis Programme, 1983.

[15] Loulou R., Goldstein G., Noble K. Documentation for the MARKAL Family of Models. IEA Energy Technology Systems Analysis Programme, 2004.

[16] Tallis H., Ricketts T., et al. InVEST 2.2.2 User's Guide: Integrated Valuation of Ecosystem Services and Tradeoffs. Stanford, The Natural Capital Project, Stanford University, 2012.

[17] Lofgren H., Diaz-Bonilla C. MAMS: An Economy-wide Model for Development Strategy Analysis. The World Bank. Washington DC, USA, 2010.

[18] Sterman J. D. Business Dynamics: Systems Thinking and Modeling for a Complex World. Boston, Irwin/McGrawHill, 2000.

[19] Bassi A. M. Using Simulation Models for Green Economy Policy Making: A Comparative Assessment. Review of Business and Economics Studies 2014:2(1):88-99.

[20] Bassi A., Bečić E., Lombardi N. An Introduction to the Assessment of Sustainable Paths, Models and Metrics. Asian Social Science 2014:10(11):17-27. doi:10.5539/ass.v10n11p17

[21] Wallhagen M., Glaumann M. Design consequences of differences in building assessment tools: a case study. Building Research \& Information 2011:39(1):16-33. doi:10.1080/09613218.2010.513210

[22] Randers J. Elements of the System Dynamics Method. Portland, OR: Productivity Press, 1980.

[23] Richardson G., Pugh A. Introduction to System Dynamics with Dynamo. Portland, OR, USA: Productivity Press, 1981.

[24] Forrester J. W., et al. Road Maps: A Guide to Learning System Dynamics, System Dynamics Group. Sloan School of Management, MIT, 2002.

[25] Roberts N., Andersen D., Deal R., Garet M., Shaffer W. Introduction to Computer Simulation. The System Dynamics Approach. Reading, MA, USA: Addison-Wesley, 1983.

[26] Probst G., Bassi A. M. Tackling Complexity, A Systemic Approach for Decision Makers. Greenleaf Publishing, Sheffield, UK, 2014.

[27] Ibarran M. E., Bassi A. M., Boyd R. Integrating SD and CGE models to assess green economy policies: Methods and Application to Mexico. In: Handbook of Research Methods and Applications in Environmental Studies. Edward Elgar Publishing, 2015.

[28] Van Paddenburg A., Bassi A., Butler E., Cosslett C., Dean A. Heart of Borneo: Investing in Nature for a Green Economy. WWF Heart of Borneo Global Initiative, Jakarta, 2012.

[29] Bassi A., Lombardi N., Gallagher L. A. Green Economy Modelling of Ecosystem Services in the DawnaTenasserim Landscape (DTL) along the "Road to Dawei". WWF Greater Mekong, 2014.

[30] Jones M. Accounting for the environment: Towards a theoretical perspective for environmental accounting and reporting. Accounting Forum 2010:34(2):123-138. doi:10.1016/j.accfor.2010.03.001

[31] De Groot R., Alkemade R., Braat L., Hein L., Willemen L. Challenges in integrating the concept of ecosystem services and values in landscape planning, management and decision making. Ecological Complexity 2010:7(3):260-272. doi:10.1016/j.ecocom.2009.10.006

[32] Boschken H. Scale, the Silo Effect and Intergovernmental Cooperation: Institutional Analysis of Global Cities and Ecological Sustainability. American Political Science Association 2013 Annual Meeting. San Jose State University, 2013. 


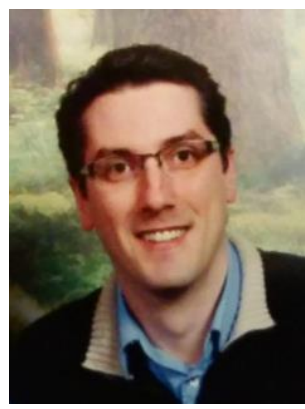

Dr. Bassi holds a Ph.D. and M.Phil. in System Dynamics at the University of Bergen, Norway, a M.Sc. in Business and Economics at LIUC, Italy, and a postgraduate course in modeling the environment at the Universitad Politecnica de Catalunia in Spain.

Dr. Andrea M. Bassi is the founder and CEO of KnowlEdge Srl and an Extraordinary Professor at Stellenbosch University, in South Africa. Dr. Bassi is a project leader and researcher, with over 15 years of experience, supporting more than 30 governments and several international organizations primarily on green economy strategies \& scenarios, climate mitigation \& adaptation and sustainable development.

Dr. Bassi is a member of the GIST Collaborative since 2012 and of The International Network of Resource Information Centers (The Balaton Group) since 2010. Dr. Bassi was also involved in the activities of the System Dynamics Society (SDS), as Co-Founder and Co-Chair of the Energy Special Interest Group, during 2006-2011. 